\title{
Curriculum of Pre-service Teacher Education in China:Problems and Strategies
}

\author{
Hui Zhang ${ }^{1, a}$, Ping Jiang ${ }^{1, b}$ \\ ${ }^{1}$ School of Educational Science, Mianyang Normal University, Mianyang, China \\ a870814893@qq.com, b464273623@qq.com
}

\begin{abstract}
Keywords: teacher education; course
Abstract. Because of the current structural imbalance in the curriculum of pre-service teacher education in China, such as old content, implementation, a single evaluation. This article aims to improve the teachers' professional quality as the center of the curriculum goal, adjust the curriculum structure, train students' professional quality, update the course content, rich curriculum form, adopt flexible and varied teaching mode, strengthen the construction of evaluation system, and promote the diversified curriculum evaluation, comprehensive countermeasures and Suggestions.
\end{abstract}

\section{Introduction}

Pre-service teacher education is necessary for students to engage in teachers' professional activities, and it is an important part of teacher education. Course is an important means of cultivating students for teachers' professional quality. Therefore, in order to improve the quality of teachers, we should have a scientific curriculum settings of the pre-service teacher education However, preservice teacher education curriculum seriously impacts on the quality of the teacher training in China.

\section{The problems of the pre-service teacher education courses in China}

The curriculum structure is imbalance, the status of educational courses is low, and the proportion is small. Pre-service teacher education curriculum in our country structurally mainly includes public basic courses, subject courses and education professional courses. In general, it has the following problems.

Firstly,the required courses and elective courses have an imbalance ratio, elective has a small proportion. In the system of pre-service teacher education courses, the compulsory courses and elective proportion are not harmonious, more equired courses, less elective courses open. Secondly, the proportion of public basic course is small, and its structure is imbalance. Public basic course that general education course includes compulsory public and public elective courses. Public course mainly include political theory course and ideological moral lesson, military theory and military training, foreign language, physical education, computers, and so on. Settings for these courses, guided by the departments in charge of education and evaluation, which accounted for about $10 \%$ of the total credit [1]. Thirdly, take discipline specialized courses seriously, despise education courses. The proportion for the specialized course of "what to teach " is too big, accounted about $60-75 \%$ of the total teaching hours.while the proportion for the "how to teach" the course of pedagogy, psychology and education scale is too small, less than $10 \%$ of the total teaching hours [2]. That cause the incomplete knowledge structure of students.

Course contents are old, single, divorced from reality. To the limitation of traditional disciplines, the pre-service teacher education curriculum content is difficult to make updates, too much emphasis on system, integrity, discipline, which lead to the forward-looking, applicability and practicality are not strong. Due to the public basic course category single, the lack of an integrated course, ignore the horizontal the knowledge jointly, resulting in science students ' lack of knowledge of the humanities, social sciences, and liberal arts students with a lack of knowledge of natural sciences. Due to a single public foundation course categories, lack of comprehensive 
curriculum, the neglect of the knowledge transverse joint between disciplines, and that cause science students are lack of knowledge of the humanities and social science, and liberal arts students are lack of knowledge of natural science. Subject professional development courses focus on discipline, fostered student discipline is strong. Courses focus on professional disciplines of deep development of academic disciplines, which cause students are discipline, comprehensive ability is not strong and the knowledge structure is single, not all graduated students can teach comprehensive course well. Education curriculum is typically based on the "old three", which is represented by pedagogy, psychology. In addition, the curriculum emphasizes system, integrity, discipline excessively, lack of practice, and make students lack enough skill training.

The effect of curriculum implementation is not good.Curriculum implementation is a key link in the process of curriculum reform, and teachers are main implementer of the course. Because our country has always attached a great importance to the political education,which occupies a big proportion in a public basic course. In addition, the discipline specialized courses in the teacher education curriculum system also has a high proportion. Therefore, the basic quality of normal colleges' graduates in our country is higher, especially has the high ideological and political quality. However, because of a shortage of the setting of teacher education curriculum in our country and the low proportion of professional education curriculum, the educational practice time is too short, leading normal graduates' interest in drab, organization and management ability is poor and so on.

Curriculum evaluation is single and quantitative. Taylor thought that course evaluation process is the process of the extent of target for the curriculum and teaching.Although China's normal colleges and universities have made some progress in the study of theory and practice of curriculum evaluation, there are still some problems: First,curriculum evaluation subject is single, and emphasizes the evaluation on administrative sense. The course evaluation activity which is opened by normal colleges and universities while there are external experts to participate in, but also has a distinct political color, more embodied in the evaluation of top-down. Second, the most are single curriculum research activities because of system evaluation organization lacking.The result will lead that it pay attention to development process, while neglect the reflection on the whole course [3]. Third,too much emphasis on the role of the study result in the evaluation.

\section{The strategy to promote the development of curriculum of Pre-service Teacher education}

Established to improve the teachers' professional quality as the center of curriculum goals. Pre-service teacher education curriculum goal is the degree of literacy for normal university student in the aspects of moral, intellectual, physical quality. Under the background of great development in today's society, identify new training objectives and specifications to satisfy the needs of The Times development, it is the key to ensure the quality of higher normal education to cultivate.

Adjust the course structure, and cultivate students' professional quality. Facing the specialized trend of teacher education curriculum in the world, the curriculum structure in China has to be reformed, in order to promote the development of teacher education curriculum reform. The main reform should undertake the following aspects:

1) Adjust the course structure, increase the proportion of education classes, reflect the professionalism of the teachers' profession

Firstly, concentrate on discipline specialized courses, increase education classes. One is compression ratio. We should condense discipline specialized course,expand the general course and education courses. The other is to reconstruct, namely on the course content, according to the characteristics of specific subjects, in line with fewer but better, knowledgeable but flux, strengthen the foundation, reflect the principles of front discipline, construct the new basic content. For education classes, we need to increase the teachers' professional skills, skills of course.The curriculum to reflect the contemporary new education idea,strengthen teacher's modern education theory and the modern education technology and education scientific research ability.

Secondly, we also need to strengthen education practice, improve the efficiency of education practice. Education expertise knowledge includes educational theory and educational practice 
knowledge.Practice course is an important approach to make students' theoretical knowledge into practical knowledge and teaching skills.

2) Open courses to meet the personalized needs of different students

After guarantee the students meet the requirements of commonality, reach the basic specification, the setting of elective courses to meet the needs of the students' individuality, let different students learn different knowledge, skills, develop different interests, hobbies, special skills, have different levels, different content combination comprehensive quality, in order to make students to be more creative teachers of primary and secondary schools, who have different teaching styles and be able to use the unique teaching methods.

\section{Update and conform curriculum content}

1) Change course content single situation, enhance its comprehensive Having comprehensive quality is one of today's innovative characteristics of primary and secondary school teachers. A single course would train this kind of teachers whose knowledge is narrow, skill is single, and hard to innovation. Thus, we must set up the "comprehensive quality" curriculum system. It shows as: the integrated curriculum. To provide students with broad general education courses, penetration and coherence in writing, make the student have a broad knowledge background. the synthesis of discipline curriculum. The setting of discipline curriculum needs to break the relevant professional curriculum system for comprehensive university, make some discipline curriculum penetration and comprehensive in mutual organically, compress the original discipline curriculum class hours.

2) Change the old course contents, vague condition, strengthen the construction of teaching material Normal colleges and universities update curriculum content, which means to streamline or increase the content of the course. Streamline doesn't mean to completely delete, it needs to be done under the premise of ensuring quality. For the current teacher education curriculum system, the need are to streamline those contents which are too abstract, and with the teachers teaching the content of the far apart; and need to increase the basic knowledge and the humanities, natural science related content (such as social studies, national culture, environmental studies), and the content of the teacher's teaching basic skills (such as teaching strategy, teaching design, education evaluation and class management), the contents related to students' development (such as child psychology, guidance and negotiation skills, human relations and art, physical training, etc. ), as well as the content of the elementary education new curriculum reform closely (such as middle and primary school study, inquiry learning guidance, the design of the integrated practical activity).

Rich curriculum forms, adopt flexible and varied teaching mode. Teaching is the main channel of curriculum implementation. Appropriate teaching mode not only helps the realization of teaching goal, masters teaching content, and can promote the cultivation of students' creative thinking and innovation ability. Thus, the recommendations for classroom teaching reform as follows:

First of all, using the rich curriculum forms. When setting courses, we should pay attention to the long-term and short-term course, also pay attention to the combination of conventional education theory, curriculum and activity curriculum, more open, such as a variety of lectures, report, project, social practice activity course of the debate, these flexible and practical courses can cultivate students' consciousness of teacher's role, increase students experience. In short, the course should reflect the characteristics of small size, diversified and comprehensive hardly.Second, the form on the carrier of knowledge, with ability of flexible and varied teaching mode. First of all, the reform of teaching methods, pay attention to cultivate the students' ability of self-study and independent thinking. Secondly, combine the knowledge learning and the cultivation of ability, cultivate students' scientific spirit and innovative thinking, let the students and teachers in curriculum development. Furthermore, improve classroom teaching methods and means, strengthening the combination of theory and practice of education.

Strengthen the construction of evaluation system, promote diversified and comprehensive course evaluation. First, strengthen the study and research on curriculum evaluation theory. 
Consensus, and lay a foundation for the full implementation of curriculum evaluation. Second, the choice of the curriculum evaluation subject diversification. The main body of diverse curriculum evaluation can prevent the disadvantages of traditional evaluation effectively, and bring actual development of the real space for evaluation object. Mobilize the different assessment subject to evaluation activities fully, education administrative departments, teachers and students in colleges and universities, relevant people from all walks of life are evaluation system of the main course. Third, the course evaluation object should reflect comprehensive. Curriculum evaluation is not only to the students' evaluation, also includes the evaluation of teachers and the curriculum itself. Fourth, the standard of curriculum evaluation should be comprehensive [4].

\section{Conclusion}

In a word, pre-service teacher education curriculum reform is the key to the reform of teacher education, and restricted by various factors.Therefore, We should know clearly that education curriculum reform and the professionalization of teachers on the objective requirement of teacher education courses,update the concept of curriculum, strengthen teacher's professional consciousness, construct the reasonable system of undergraduate course,let high quality teachers in normal universities fully play and promote the important role in the process of the specialization of teachers.

\section{Acknowledgment}

This work was supported by the project of Sichuan Province Social Science Plan (SC15XK070), and Sichuan Center for Education Development Research (CJF16008).

\section{References}

[1] Choi Sung-hak, Yu Aizong: Comparison and Enlightenment of the Curriculum in China, South Korea and Japan , Journal of the Foreign Educational Research( 2007)

[2] Shen Jiliang, Li Qiong: Opinion of Curriculum Reform from Primary and Middle School Teachers, Journal of Curriculum,Teaching Materials and Method,(2011) .

[3] Liu zhijun: The Situation, Problems and Prospect of Curriculum Evaluation. Journal of Curriculum,Teaching Materials and Method,(2007).

[4] Lv Da: The Curriculum Research and Reform in China in the 21st Century, the people's education Publishers(2001). 